\title{
Parenting and personality disorder: clinical and child protection implications
}

\author{
Gwen Adshead
}

\begin{abstract}
SUMMARY
I review some of the evidence that parental personality disorder represents a risk to child development, in terms of both transmission of genetic vulnerability and the environmental stress of living with a parent who has a personality disorder that negatively affects their parenting capacities. I argue that there are two compelling reasons to impose a duty on mental healthcare providers to offer services for adults with personality disorders that specifically focus on their parenting identity: first, because effective therapies for personality disorder are now available; and second, because there is a strong utilitarian and economic argument for improving parental mental health so as to reduce the economic and psychological burden of their offsprings' future psychiatric morbidity.
\end{abstract}

\section{LEARNING OBJECTIVES}

- Be better able to consider whether any parents assessed have a personality dysfunction

- Understand how parental personality dysfunction may influence child development

- Be better prepared to make referrals of parents to psychological therapy services

\section{DECLARATION OF INTEREST}

None

Mental dysfunction in childhood and adolescence is thought to be the result of an interaction between genetic vulnerabilities and environmental stressors (National Scientific Council on the Developing Child 2010). Although 'environments' are often thought of in purely physical terms, the developmental environment for a child includes the mental states of both parents and their attitudes towards their children. In this article, I will focus on a major environmental stressor for a child, namely the impact of living with a parent who has a personality disorder.

\section{The effect of mental disorders on parenting}

Parenting is a complex social activity; and like other forms of occupation, it is likely to be at least affected, and at worst, impaired by mental ill health. A report on parenting and mental health comments that parenting "is the hardest job in the world' because it requires an individual to balance appropriate limits and boundaries with maximal affection and attuned nurturing (Royal College of Psychiatrists 2011: p. 13). Parents do not have to be perfect carers, but they do need to provide generally 'good-enough' care (Box 1) to help their children (a) learn to self-soothe when they are angry or distressed and (b) form other healthy relationships throughout life.

Parenting carries a demanding job specification and requires that parents are in reasonable psychological health. Specifically, they need to be able to manage their own negative emotions and not respond to stress or distress in others (especially children) with rage, hostility, cruelty or panic. Parents need to have good realitytesting capabilities, be able to tolerate waiting and uncertainty and be able to work with other adults

BOX 1 Psychological capacities needed for 'good-enough' parenting

- The capacity to manage one's own distress and anxiety without becoming angry, hyperaroused or frightened

- The capacity to plan and think ahead

- The capacity to respond empathically and confidently to another person's distress

- The capacity to work with other adults involved in the child's welfare (family, professionals, parents of peers)

- The capacity to perceive vulnerability with compassion and concern

- The capacity to ask for and value help

- The capacity to tolerate negative affects (including anger, disappointment, fear, boredom, frustration, minor pain) without taking impulsive action or assuming the worst

- The capacity to tolerate waiting for own needs to be met

- A sense of humour and capacity for pleasure

\section{ARTICLE}

Gwen Adshead is a consultant forensic psychiatrist with Southern Health NHS Foundation Trust. She has regularly assessed parents with personality disorders for the family courts and is involved in evaluating a therapy group for mothers with personality disorder. Correspondence DrGwen Adshead, Locum Consultant Forensic Psychiatrist, Southern Health NHS Foundation Trust, Ravenswood House, The Knowle, Fareham P017 5NA, UK. Email: gwen.adshead@ southernhealth.nhs.uk 
who may be part of the child's life. Most of all, they need to be both empathic and sympathetic towards ongoing vulnerability and dependence: the sort of dependence that, in children, inevitably leads to repeated requests for attention.

As in any other job, normal life events may temporarily disrupt parenting skills even in the most resilient of parents. Bereavement, relationship breakdown, job stress, physical illness or mild degrees of mental disorders may all lead to temporary impairments of parenting performance. More severe mental disorders may lead to more substantial impairments of parenting function (as discussed in Royal College of Psychiatrists 2011). The good news is that only a small minority of parents will have mental disorders that may adversely affect their parenting. The prevalence of mental disorder in parents is reported to be 9-10\% for mothers and 5-6\% for fathers; the most common diagnoses will be depression or anxiety and less than $0.5 \%$ will be psychotic disorders (Royal College of Psychiatrists 2011).

\section{Parental personality disorder: current data}

An adult's personality is a key aspect of their parenting capacity because of the role of personality function in terms of regulating affect, arousal and social relationships, including relationships with dependent others (Belsky 1984; Livesley 2007). It is therefore reasonable to assume that disorders of personality function will have an impact on parenting behaviours and outcomes for children in a variety of ways.

\section{Direct effects of parental personality disorder on children's behaviour and mental health}

Studies going back almost 50 years (Wolff 1968; Rutter 1984) found evidence that parental personality disorder is associated with hostility towards children, which in turn increases the risk of mental disorders in the child. Later studies of parents of children referred to child and adolescent mental health services (CAMHS) continue to find high levels of parental personality pathology. High levels of antisocial personality disorder in both mothers and fathers have been found in studies of parents of children diagnosed with conduct disorder or oppositional defiant disorder (Lahey 1988, 1989; Frick 1992; Nigg 1998). Weiss et al (1996) found that children of mothers with borderline personality disorder had more psychiatric diagnoses and poorer impulse control than children of mothers without such disorders; and similarly, children of mothers with both antisocial traits and depression had more problems than children of mothers who had either antisocial traits or depression (Kim-Cohen 2006). Berg-Nielsen \& Wichström (2012) report that selfreported personality disorder traits in parents are associated with externalising behaviour in their children. Finally, follow-up studies of children in 'high-risk families' found that parental personality disorder predicted adolescent personality disorder, a relationship mediated by maladaptive parenting behaviours (Johnson 2001).

\section{Direct effects of parental personality disorder: risk to child welfare through maltreatment}

Although the majority of people with personality disorder pose no risk of harm to others, some types of personality disorder (especially antisocial and narcissistic) may be associated with risk of harm to vulnerable or dependent others. Retrospective cohort studies of maltreating parents often find high prevalence (60-70\%) of personality disorder (Taylor 1991; Famularo 1992; Dinwiddie 1993; Stanley 1999). Although some of these studies may suffer from a degree of sampling bias and post hoc reasoning, their findings mirror evidence from the forensic literature that suggests that parental personality disorder is a risk factor for family violence and child maltreatment in certain circumstances: usually when parental cluster $\mathrm{B}$ disorders (Box 2) occur in combination with substance misuse and environmental stress. In particular, fathers with antisocial personality disorder may become involved with mothers who have borderline personality disorder; these couples are more likely to be involved in domestic violence, which increases the risk of all forms of child maltreatment within the home.

\section{Indirect effects of parental personality disorder: maternal behaviours}

Somatising, eating disorders and fabrication of illness

Mothers with personality disorder may display a variety of abnormal behaviours that affect their children's development. For example, there is a

BOX 2 DSM-5 clusters of personality disorders

Cluster A : Odd or eccentric behaviours (schizoid, paranoid and schizotypal)

Cluster B: Flamboyant to dramatic behaviours (antisocial, borderline, narcissistic and histrionic)

Cluster C: Fearful and anxious behaviours (avoidant, dependent and obsessive-compulsive)

(American Psychiatric Association 2013) 
close association between personality disorder and somatising disorder (Stern 1993; Bornstein 2008); and there is evidence that somatising mothers struggle to respond to their children's needs, and may increase the risk of somatising behaviours in their children (Craig 2002, 2004; Marshall 2007). A subgroup of mothers with personality disorder also have symptoms of eating disorders, which can give rise to dysfunctional control over their children's food and influence the children's eating patterns (Stein 1999).

There are particular concerns about the relationship between maternal personality disorder and highly abnormal illness behaviour that involves deceptions and claiming children are ill when they are not. One study of mothers who demonstrated such highly abnormal and risky illness behaviour involving their children found that over 50\% of these women had either somatising disorder or personality disorder (especially borderline personality disorder) (Bools 1994).

\section{Disorganised family planning}

Finally, maternal personality disorder may have an indirect effect on child development through an effect on how families are planned and constituted. Women with borderline personality disorder typically make intense and unstable emotional relationships with other adults: relationships that are often associated with high levels of threat perception, negative emotionality and fear. Women with borderline personality disorder who are of child-rearing age (potentially span of more than 20 years) may become pregnant while emotionally involved with a man, only to break up with him soon after they have the child, often in the context of claims of domestic violence. It is therefore not uncommon for a mother with borderline personality disorder to have multiple children by different male partners, none of whom is present in her life. She is then a socially disadvantaged mother, who will be vulnerable to comorbid depression through having to care for multiple children under the age of 10 while she herself lacks secure attachments.

The extent of the problem is starkly demonstrated in an ongoing therapy programme for socially disadvantaged mothers with which I am involved (further details available on request). In the 2 years that the project has been running, 21 mothers (all with personality disorders), who between them have 96 children, have been offered treatment. All but one of these women have been involved in care proceedings at some point in their history, at an average cost of $£ 25000$ per child taken into care (Department for Education and Skills 2006). Some women have had three or more children removed.

\section{The impact of personality disorder as a growth 'environment'}

\section{Orchids and dandelions}

During childhood, children develop and 'grow' a mind: a set of psychological capacities that regulate their internal psychology and their social psychological skills. Parental behaviour and mental state is the 'environment' that immediately interacts with the child's genetic vulnerability or resilience to influence the development of mind and mental capacity.

The 'orchid-dandelion' hypothesis of child development (Ellis 2008) suggests that there are some 'environments' that will damage even the most resilient child. Parental harshness, chronic hostility and a rejecting stance are behaviours or attitudes that appear to be particularly negative or hazardous 'environments' for the developing child. These are also states of mind or behaviours that may be more common in parents with personality disorders and that give rise to those types of 'maladaptive parental behaviour' associated with high rates of child and adolescent psychopathology (Johnson 2001).

\section{Brain chemistry and attachment}

Research in epigenetics has shown how parental rearing behaviours lead to different DNA methylation patterns in different parts of the offspring brain (van IJzendoorn 2011; Perroud 2014). Furthermore, a parent's genetic profile affects their levels of neurotransmitters (especially cortisol, serotonin and oxytocin), influencing parenting behaviours (Vanyukov 1993; Bakermans-Kranenburg 2008; Galbally 2011).

Parental behaviour that promotes secure attachment between adult and child may promote resilience in children (Yates 2003). Parental behavioural sensitivity affects the development of attachment in offspring (van IJzendoorn 1995); 'sensitivity' includes the full range of parental responses to a child's behavioural and verbal cues, and especially the way that a parent reacts to their own stress or the stress of others. Positive and attuned sensitivity to a child's distress promotes secure attachment; but frightened or frightening parenting behaviours lead to disorganised attachment in children, which in turn is associated with a range of abnormal childhood behaviours and childhood psychopathology (van IJzendoorn 1999).

In the past 10 years, fine-grained studies of the impact of maternal borderline personality disorder 
on mother-baby relationships have shown how negative effects might be mediated by disruptions in mother-infant communication, even in the first weeks and months of life (Lyons-Ruth 2005; Hobson 2009). Parents with borderline personality disorder have poor affect and arousal regulation, which means that they are at risk of getting into hostile and helpless states of mind (Lyons-Ruth 2007) that have a negative impact on children's attachment systems. These same hostile/helpless states of mind have also been found to be more common in mothers who maltreat their children (Frigerio 2013). If the parent feels helpless and hostile, they are more likely to treat their child as an adult or peer, which may lead to role-reversal or attack behaviours.

\section{G $\times$ E interaction and genetic vulnerability}

Foley et al (2004) suggest that parental personality disorder acts passively in gene-environment $(\mathrm{G} \times \mathrm{E})$ interactions by making all forms of adverse childhood environments more likely. Parents with moderate degrees of personality disorder are at increased risk of premature death from suicide and violence; may be socially deprived and involved in crime; are more likely to be involved in relationships that break down; and are at increased risk of poor physical health. Any children of adults with even a moderate degree of personality disorder may therefore be exposed to environmental and social adversity that interacts with genetic vulnerability to produce disorder.

Parental personality disorder may also be inherited directly through transmission of vulnerability genes. Personality traits are known to be highly heritable, so children of parents with genes that influence personality will inherit those genes (or some version of them). These children then are exposed to a 'double whammy' of adversity because their parents' personality traits adversely affect parenting behaviours and increase the risk of childhood disorder, as described above.

\section{Service provision}

Unfortunately, there is little practical information about how best to provide services for parental personality disorder. For example, an extensive review of parental mental health by Tunnard (2004) makes little reference to personality disorder in parents; nor does a recent Ofsted report (2013), which makes recommendations about how mental health services should work with local child safeguarding boards. National Institute for Health and Care Excellence guidelines for the treatment of personality disorder (NICE 2009a,b) do not include any reference to the need to provide specific interventions relating to parenting, even though personality disorder principally affects adults of childbearing age (as it usually remits in severity in older age).

Parental personality disorder is often first identified when families come to the attention of child protection services, and local authorities seek to take children at risk into care. In the UK there are a few specialist teams that offer extended and in-depth assessment of such families (e.g. at the Anna Freud Centre, Great Ormond Street Hospital and the Maudsley Hospital in London and the Family Assessment and Safeguarding Service, which covers Oxfordshire, Wiltshire, Buckinghamshire and Bath \& North East Somerset). These services are not always able to offer therapy to parents involved, especially if the family is broken up in the context of proceedings.

There is an odd disparity of services compared with services offered to women with post-natal psychoses. Mothers with psychotic disorders are offered specific services with in-patient treatment and community follow-up, and rightly so because of concerns about risk to children. However, mothers with personality disorders are not likely to be offered a similarly specific service, even though some of the same risk issues may apply and personality disorder is "no longer a diagnosis of exclusion' for services (National Institute for Mental Health in England 2003). The absence of services is concerning, given the evidence that the presence of personality disorder in a parent compromises parenting to the same extent as severe mental illness does, and perhaps even more (Berg-Nielsen 2002; Johnson 2006).

\section{Interventions and action plans}

\section{Treating the personality dysfunction}

There is ample evidence that personality disorders can remit with appropriate treatment (reviewed in Sarkar 2012), and NICE treatment guidelines are available for borderline personality disorder and antisocial personality disorder (NICE 2009a,b). In borderline personality disorder, mild to moderate degrees of disorder appear to respond well to a range of therapeutic interventions, whereas more severe disorder seems to respond better to more intensive forms of therapy such as mentalisationbased treatment (Stoffers 2012; Bateman 2013). Cluster A and cluster C personality disorders (Box 2) may be treatable with general interventions that address metacognitive function.

\section{Screening}

It may be helpful for both adult mental health services and CAMHS to screen parents for 
the presence of personality disorder. Possible tools include the Standardised Assessment of Personality-Abbreviated Scale (SAPAS; Moran 2003) and the ICD-10 International Personality Disorder Examination (IPDE) Screening version (Loranger 1997). Tools like this can help clinicians identify behaviours and attitudes for intervention. CAMHS may consider using the IPDE (Loranger 1994) screening questionnaire, which is widely used in epidemiological research and also by some psychological therapy services. It is not a diagnostic tool, but high scores on any of the scales indicate that further assessment of personality dysfunction is warranted.

\section{Addressing relationships and parenting skills}

In addition to therapies for personality dysfunction, parents with personality disorders need interventions that can address their relationships with their children and their parenting skills, and thus reduce the severity of their children's distress. Psychological therapies need to focus on improving the capacities described in Box 1, many of which would be subsumed within the concept of mentalising and self-reflective function. There is some promising evidence for the efficacy of interventions that promote parental mentalising (e.g. Nijssens 2013). Mindfulness practices may also be helpful to parents with personality disorders whose level of hostility towards themselves and their children suggests a lack of compassion for the self and others (Shonin 2013). Interventions that use video feedback have also demonstrated good results, as have those that promote children's resilience and welfare (Cooklin 2013).

\section{Service provision}

These interventions and services are also essential to improve child protection. Parents who perpetrate the type of fatal child abuse that hits the media headlines usually have histories with features typical of personality disorder, usually both borderline and antisocial types. However, it is almost impossible to access treatment for abusive parents with personality disorders, especially if the abuse is non-fatal or involves neglect. In my work as an expert witness in child protection cases, I have found that these parents are rejected by every service: they are not deemed 'forensic enough' for forensic services (especially since they rarely require secure in-patient care), and community mental health teams usually reject them on the grounds that they do not have a mental illness. Most CAMHS no longer offer therapy to parents; and not every area has specialist psychological therapy or complex needs services. Those that do may be reluctant to work with parents who have histories of child abuse or who are involved with Social Services.

It must also be said that abusive parents with personality disorders may be hard to engage. They may feel defensive and reluctant to accept their difficulties and need to build up a trusting relationship over time with healthcare professionals. In this sense, they resemble forensic patients, who are often similarly hard to engage, wary and in need of long-term support. They also resemble forensic patients in that they are often involved in a range of legal proceedings, both criminal and child protection.

It is therefore puzzling that forensic services do not offer interventions for abusive parents with personality disorders. It is particularly so because psychological interventions for other offenders with personality disorders are being developed and rolled out in prisons and the community. These new psychologically informed planned environments (PIPES) programmes (National Offender Management Service 2012) are being developed using monies ( $£ 69$ million) that were previously made available to treat people whose severe personality disorder made them a danger to others. If these male and female offenders with personality disorders can access a service that aims to help them desist from offending and develop more prosocial lives, it seems odd that there are no equivalent services for parents whose personality disorders lead them to be dangerous to their children.

It will be argued that parenting programmes have been developed for struggling families, including the Troubled Families Initiative (Department for Communities and Local Government 2012) for hard-to-reach families, and the multisystemic therapy (MST) projects (Department for Education 2011) for families where there is a young person with emerging antisocial traits. However, families where there is a parent with personality disorder are often excluded from such programmes, as their problems are seen as too complex, especially if they are involved in legal proceedings or have histories of violence. Most parenting programmes do not focus on personality disorder symptom reduction or control; nor do they offer specific techniques for improving affect regulation or reflective function when managing the distress of children.

\section{Conclusions and recommendations}

\section{Financial implications}

Data from the Office for National Statistics indicate that there are about 15 million women of childbearing age in England and Wales; and last 
year just over 600000 babies were born to mothers in England and Wales (Office for National Statistics 2014). If $2 \%$ of these mothers have personality disorders of at least moderate severity, then 12000 women will need services that offer high-quality therapeutic interventions. These interventions will not just address their personality dysfunction, but must also try to reduce the impact of that dysfunction on their parenting skills and child abuse potential. These will be mothers who are at increased risk of having a child (and possibly more than one) taken into care. The legal costs of completed care proceedings vary, but are in the region of $£ 23000$ (Beckett 2014). If half of those mothers had a child taken into care, the cost would be over $£ 13$ million annually. Compare this with the $£ 67$ million made available for therapy programmes for offenders with personality disorders by the National Offender Management Service (2012).

\section{Assessment and treatment teams}

It should be perfectly possible to commission teams who would work jointly with several local

BOX 3 Five take-home messages for commissioners

- Just as for other mental disorders, diagnosis alone conveys nothing about risk. The majority of individuals with personality disorders may be able to care for their children with help, and are not a risk to them.

- One-off assessments of personality disorder are notoriously unreliable. Although there is no good agreement about the gold standard for personality disorder assessment, there are some instruments that have reasonable psychometric properties and in any event will be an improvement on clinical assessment alone. Repeat or multiprofessional assessment is optimal.

- There are now effective treatment programmes for mild to moderate degrees of personality disorder, especially borderline personality disorder (Sarkar 2012). There is no evidential basis for saying that personality disorder is untreatable.

- It is vitally important that psychiatrists engage in the active treatment of parents with personality disorders, especially mothers. Capacity to parent may be significantly improved with both psychological therapies that improve affect regulation and impulsivity (such as dialectical behaviour therapy and mentalisation-based treatment) and adequate pharmacological therapy.

- Commissioners will appreciate that provision of treatments for parents with personality disorders now may lead ultimately to greater savings in the future, in terms of reduced service utilisation and improved mental health of the next generation. authority safeguarding services and mental health trusts (a) to provide consultation for social workers and other professionals working with parents with personality disorder, and (b) to offer early interventions, both with younger parents and when professional anxieties are first raised about a parent's capacity to provide child care. They could also act as leads for child protection and safeguarding.

These professional teams (which might have a regional remit) would be able to assess and treat personality disorder; they would also need to be able to assess risk of adults causing harm to others, especially children. They could liaise with the family courts in the same way that mental health teams work with the magistrates courts to divert offenders out of the criminal justice system; in doing so, they could reduce the costs and the time taken in getting psychiatric expert assessments. They would need to be able to work collaboratively across a range of disciplines and services, keeping both children and adults in mind. The Family Drug and Alcohol Court (FDAC) programme (Tavistock and Portman NHS Foundation Trust 2014) is a potential model for such a service. It has had some success in helping parents with substance misuse (most of whom will have some degree of personality dysfunction) improve their parenting (Bambrough 2014).

\section{Commissioning specialist services for parents with personality dysfunction}

It will be argued that such projects are too expensive to develop at a time when mental health services are being cut. But commissioners can be persuaded of the value of commissioning services that may reduce the health burden in the long term: for example, the development of new liaison psychiatry posts to deal with medically unexplained conditions. A King's Fund report into the costs of mental healthcare estimated that the cost of treating adult personality disorder (which was $£ 704$ million in 2007) is projected to rise to $£ 1.1$ billion in 2026; and that the costs of treating children's psychiatric disorders is projected to rise by $13.3 \%$ (McCrone 2008). Any interventions for parents with personality disorders that could reduce the prevalence of either personality disorder or children's disorders by even one percentage point would pay for themselves in the long term; and improve the lives of adults and children, now and in the future. Take-home messages for commissioners are set out in Box 3. We may well ask whether we can afford not to treat parental personality disorder with the same vigour with which we treat mothers with psychoses and offenders with personality disorders. 


\section{References}

American Psychiatric Association (2013) Diagnostic and Statistical Manual of Mental Disorders (5th edn) (DSM-5). APA.

Bakermans-Kranenburg MJ, van IJzendoorn MH (2008) Oxytocin receptor (OXTR) and serotonin transporter (5-HTT) genes associated with observed parenting. Social Cognitive and Affective Neuroscience, 3: 128-34.

Bambrough S, Shaw M, Kershaw S (2014) The Family Drug and Alcohol Court service in London: a new way of doing Care Proceedings. Journal of Social Work Practice, 28: 357-70.

Bateman A, Fonagy P (2013) Impact of clinical severity on outcomes of mentalisation-based treatment for borderline personality disorder. British Journal of Psychiatry, 203: 221-7.

Beckett C, Dickens J, Bailey S (2014) Concluding Care Proceedings Within 26 Weeks: Messages from the Evaluation of the Tri-borough Care Proceedings Pilot. Centre for Research on Children \& Families/University of East Anglia.

Belsky J (1984) The determinants of parenting: a process model. Child Development, 55: 83-96.

Berg-Nielsen TS, Vikan A, Dahl AA, et al (2002) Parenting related to child and parental psychopathology: a descriptive review of the literature. Clinical Child Psychology and Psychiatry, 7: 529-52.

Berg-Nielsen TS, Wichström L (2012) The mental health of preschoolers in a Norwegian population-based study when their parents have symptoms of borderline, antisocial, and narcissistic personality disorders: at the mercy of unpredictability. Child and Adolescent Psychiatry and Mental Health, 6: 1-13.

Bools C, Neale B, Meadow R (1994) Munchausen's syndrome by proxy: a study of psychopathology. Child Abuse and Neglect, 18: 773-88.

Bornstein RF, Gold SH (2008) Comorbidity of personality disorders and somatization disorder: a meta-analytic review. Journal of Psychopathology and Behavioral Assessment, 30: 154-61.

Cooklin A (2013) Promoting children's resilience to parental mental illness: engaging the child's thinking. Advances in Psychiatric Treatment, 19: 229-40.

Craig TKJ, Cox AD, Klein K (2002) Intergenerational transmission of somatization behaviour: a study of chronic somatizers and their children. Psychological Medicine, 32: 805-16.

Craig TKJ, Bialas I, Hodson S, et al (2004) Intergenerational transmission of somatization behaviour: 2. Observations of joint attention and bids for attention. Psychological Medicine, 34: 199-209.

Department for Communities and Local Government (2012) The Troubled Families Programme: Financial Framework for the Troubled Families Programme's Payment-by-Results Scheme for Local Authorities. TSO (The Stationery Office).

Department for Education (2011) Multisystemic Therapy (MST). DfE (http://www.education.gov.uk/commissioning-toolkit/Content/PDF/ Multisystemic\%20Therapy.pdf).

Department for Education and Skills, Department for Constitutional Affairs (2006) Review of the Child Care Proceedings System in England and Wales. DfES/DCA.

Dinwiddie S, Bucholz K (1993) Psychiatric diagnoses of self-reported child abusers. Child Abuse and Neglect, 17: 465-76.

Ellis BJ, Boyce WT (2008) Biological sensitivity to context. Current Directions in Psychological Science, 17: 183-7.

Famularo R, Kinscherff R, Fenton T (1992) Psychiatric diagnoses of abusive mothers: a preliminary report. Journal of Nervous and Mental Disease, 180: 658-61.

Foley DL, Eaves LJ, Wormley B, et al (2004) Childhood adversity, monoamine oxidase a genotype, and risk for conduct disorder. Archives of General Psychiatry, 61: 738-44.

Frick PJ, Lahey BB, Loeber R, et al (1992) Familial risk factors to oppositional defiant disorder and conduct disorder: parental psychopathology and maternal parenting. Journal of Consulting and Clinical Psychology, 60: 49-55.

Frigerio A, Costantino E, Ceppi E, et al (2013) Adult attachment interviews of women from low-risk, poverty, and maltreatment risk samples: comparisons between the hostile/helpless and traditional AAl coding systems. Attachment and Human Development, 15: 424-42.

Galbally M, Lewis AJ, IJzendoorn MV, et al (2011) The role of oxytocin in mother-infant relations: a systematic review of human studies. Harvard Review of Psychiatry, 19: 1-14.

Hobson RP, Patrick MPH, Hobson JA, et al (2009) How mothers with borderline personality disorder relate to their year-old infants. British Journal of Psychiatry, 195: 325-30.

Johnson JG, Cohen P, Kasen S, et al (2001) Association of maladaptive parental behavior with psychiatric disorder among parents and their offspring. Archives of General Psychiatry, 58: 453-60.

Johnson JG, Cohen P, Kasen S, et al (2006) Maternal psychiatric disorders, parenting, and maternal behavior in the home during the child rearing years. Journal of Child and Family Studies, 15: 97-114.

Kim-Cohen J, Caspi A, Rutter M, et al (2006) The caregiving environments provided to children by depressed mothers with or without an antisocial history. American Journal of Psychiatry, 163: 1009-18.

Lahey BB, Piacentini JC, McBurnett K, et al (1988) Psychopathology in the parents of children with conduct disorder and hyperactivity. Journal of the American Academy of Child \& Adolescent Psychiatry, 27: 163-70.

Lahey BB, Russo MF, Walker JL, et al (1989) Personality characteristics of the mothers of children with disruptive behavior disorders. Journal of Consulting and Clinical Psychology, 57: 512-5.

Livesley WJ (2007) A framework for integrating dimensional and categorical classifications of personality disorder. Journal of Personality Disorders, 21: 199-224.

Loranger AW, Sartorius N, Andreoli A, et al (1994) The International Personality Disorder Examination: the World Health Organization/ Alcohol, Drug Abuse, and Mental Health Administration international pilot study of personality disorders. Archives of General Psychiatry, 51: 215-24.

Loranger AW, Janca A, Sartorius N (eds) (1997) Assessment and diagnosis of personality disorders: The ICD-10 International Personality Disorder Examination (IPDE). Cambridge University Press.

Lyons-Ruth K, Yellin C, Melnick S, et al (2005) Expanding the concept of unresolved mental states: hostile/helpless states of mind on the Adult Attachment Interview are associated with disrupted motherinfant communication and infant disorganization. Development and Psychopathology, 17: 1-23.

Lyons-Ruth K, Melnick S, Patrick M, et al (2007) A controlled study of Hostile-Helpless states of mind among borderline and dysthymic women. Attachment and Human Development, 9: 1-16.

Marshall T, Jones DPH, Ramchandani PG, et al (2007) Intergenerational transmission of health beliefs in somatoform disorders: exploratory study. British Journal of Psychiatry, 191: 449-50.

McCrone P, Dhanasiri S, Patel A, et al (2008) Paying the Price: The Cost of Mental Health Care in England to 2026. King's Fund.

Moran P, Leese M, Lee T, et al (2003) Standardised Assessment of Personality - Abbreviated Scale (SAPAS): preliminary validation of a brief screen for personality disorder. British Journal of Psychiatry, 183: 228-32. National Institute for Health and Clinical Excellence (2009a) Antisocial Personality Disorder: Treatment, Management and Prevention (NICE Clinical Guideline 77) (September 2013). NICE.

National Institute for Health and Clinical Excellence (2009b) Borderline Personality Disorder: Treatment and Management (NICE Clinical Guideline 78). NICE.

National Institute for Mental Health in England (2003) Personality Disorder: No Longer a Diagnosis of Exclusion. Policy Implementation Guidance for the Development of Services for People with Personality Disorder. Department of Health/NIMHE.

National Offender Management Service, Department of Health (2012) A Guide to Psychologically Informed Planned Environments. National Offender Management Service/Department of Health.

National Scientific Council on the Developing Child (2010) Early Experiences Can Alter Gene Expression and Affect Long-Term Development (Working Paper No. 10). Center on the Developing Child, Harvard University.

\section{MCO answers \\ 1 d $\quad 2$ b 3 e $\quad 4$ b 5 a}


Nigg JT, Hinshaw SP (1998) Parent personality traits and psychopathology associated with antisocial behaviors in childhood attentiondeficit hyperactivity disorder. Journal of Child Psychology and Psychiatry, 39: $145-59$.

Nijssens L, Luyten P, Bales DL (2013) Mentalization-based treatment for parents (MBT-P) with borderline personality disorder and their infants. In Minding the Child: Mentalization-Based Interventions with Children, Young People and Their Families (eds N Midgley, I Vrouva): 79-97. Routledge.

Office for National Statistics (2014) Births in England and Wales, 2013 (Statistical Bulletin). ONS (http://www.ons.gov.uk/ons/ dcp171778_371129.pdf)

Ofsted (2013) What about the Children? Joint Working between Adult and Children's Services when Parents or Carers have Mental III Health and/or Drug and Alcohol Problems. Ofsted.

Perroud N, Dayer A, Piguet C, et al (2014) Childhood maltreatment and methylation of the glucocorticoid receptor gene NR3C1 in bipolar disorder. British Journal of Psychiatry, 204: 30-5.

Royal College of Psychiatrists (2011) Parents as Patients: Supporting the Needs of Patients who are Parents and Their Children (College Report CR164). Royal College of Psychiatrists.

Rutter M, Quinton D (1984) Parental psychiatric disorder: effects on children. Psychological Medicine, 14: 853-80.

Sarkar J, Adshead G (2012) Clinical Topics in Personality Disorder. RCPsych Publications.

Shonin E Van Gordon W, Slade K, et al (2013) Mindfulness and other Buddhist-derived interventions in correctional settings: a systematic review. Aggression and Violent Behavior, 18: 365-72.

Stanley N, Penhale B (1999) The mental health problems of mothers experiencing the child protection system. Child Abuse Review, 8: 34-45.

Stein A, Woolley H, McPherson K (1999) Conflict between mothers with eating disorders and their infants during mealtimes. British Journal of Psychiatry, 175: 455-61.

Stern J, Murphy M, Bass C (1993) Personality disorders in patients with somatisation disorder. A controlled study. British Journal of Psychiatry, 163: 785-9.
Stoffers JM, Völlm BA, Rücker G, et al (2012) Psychological therapies for people with borderline personality disorder. Cochrane Database of Systematic Reviews, 8: CD005652.

Tavistock and Portman NHS Foundation Trust (2014) Family drug and alcohol court. Tavistock and Portman (http://www.tavistockandportman. nhs.uk/care-and-treatment/information-parents-and-carers/our-clinicalservices/family-drug-and-alcohol). Accessed 8 Nov 2014

Taylor CG, Norman DK, Murphy JM, et al (1991) Diagnosed intellectual and emotional impairment among parents who seriously mistreat their children: prevalence, type, and outcome in a court sample. Child Abuse and Neglect, 15: 389-401.

Tunnard J (2004) Parental Mental Health Problems: Messages from Research, Policy and Practice. Research in Practice.

van IJzendoorn M (1995) Adult attachment representations, predictive responsiveness and infant attachment: a meta-analysis of the predictive validity of the Adult Attachment Interview. Psychological Bulletin, 117: 387-403.

van IJzendoorn M, Schuengel CS, Bakermans-Kranenburg MJ (1999) Disorganized attachment in early childhood: meta-analysis of precursors, concomitants, and sequelae. Development and Psychopathology, 11: 225-49

van IJzendoorn, MH, Bakermans-Kranenburg MJ, Ebstein RP (2011) Methylation matters in child development: toward developmental behavioral epigenetics. Child Development Perspectives, 5: 305-10.

Vanyukov MM, Moss HB, Plail JA, et al (1993) Antisocial symptoms in preadolescent boys and in their parents: associations with cortisol. Psychiatry Research, 46: 9-17.

Weiss M, Zelkowitz P, Feldman RB, et al (1996) Psychopathology in offspring of mothers with borderline personality disorder: a pilot study. Canadian Journal of Psychiatry/La Revue Canadienne de Psychiatrie, 41. 285-90.

Wolff S, Acton WP (1968) Characteristics of parents of disturbed children. British Journal of Psychiatry, 114: 593-601.

Yates TM, Egeland B, Sroufe A (2003) Rethinking resilience: a developmental process perspective. In Resilience and Vulnerability: Adaptation in the Context of Childhood Adversities (ed SS Luthar): 243 66. Cambridge University Press

\section{MCOs}

Select the single best option for each question stem

\section{The prevalence of mental disorder in parents is thought to be:}
a $70 \%$
b $50 \%$
c $30 \%$
d $10 \%$
e $100 \%$.

2 High rates of personality dysfunction have been found in the parents of children referred for:

a autism spectrum disorder

b conduct disorder

c growth delay

d depression

e anxiety.
3 Parental personality disorder affects child development in the following ways:

a direct transmission of genes that increase vulnerability to personality disorder

b parental personality disorder leads to increased parental hostility towards children

c dysfunctional parental behaviour affects the expression of vulnerability and resilience genes in children

d parents with personality dysfunction may struggle to provide secure physical environments for children

e all of the above.

4 What percentage of parents who abuse their children are reported to have a personality disorder diagnosis?

a $100 \%$

b $70 \%$ c $60 \%$

d $30 \%$

e $10 \%$

5 Which of these statements is false?

a Personality disorder in adults is untreatable

b There are a range of effective therapies for mild to moderate degrees of adult personality disorder

c There is inequity of service provision between mothers with psychotic disorders and mothers with personality disorders

d Adequate treatment for parental personality disorder would reduce mental health service costs in the future

e Current failure to provide treatment for parental personality disorder is costly for social care. 